Research Square

\title{
Effects of Tidal Volume on Physiology and Clinical Outcomes of Surgery Patients Undergoing One-lung Ventilation: A Meta-analysis of Randomized Controlled Trials
}

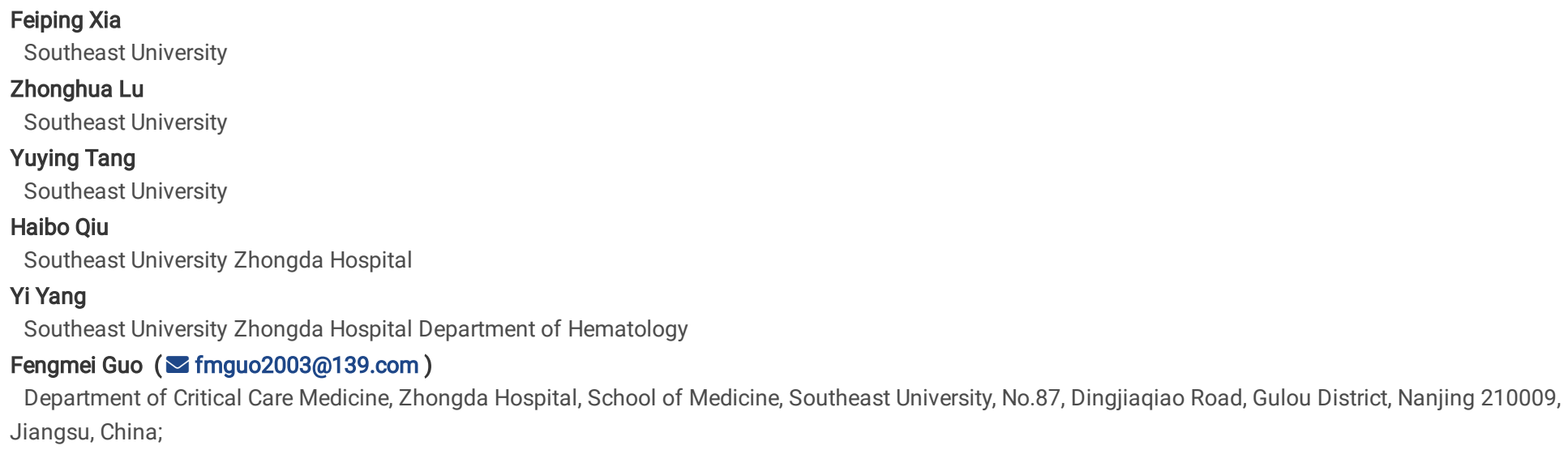




\section{Abstract}

Objective: It is unclear how tidal volume (Vt) impacts patients during one-lung ventilation (OLV). A meta-analysis was performed to assess the effect of Vt on physiology and clinical outcomes in OLV patients.

Methods: PubMed, Cochrane library, and Web of Science were retrieved until February 2020. Randomized controlled trials comparing the application of low and high Vt ventilation in adults with OLV were included. Demographic variables, Vt, physiology, and clinical outcomes were retrieved. Summary odds ratios (ORs) with 95\% confidence intervals (Cls) and mean difference with standard deviation were calculated using a random-effects model.

Results: 12 studies involving a total of 876 participants met inclusion criteria. Significant difference in blood interleukin-6 (IL-6) was observed between low Vt ventilation and high Vt ventilation ( $\mathrm{MD}-35.51 \mathrm{pg} / \mathrm{ml}, 95 \% \mathrm{Cl}[-66.47,-4.54 \mathrm{pg} / \mathrm{ml}], p=0.02)$. Low Vt ventilation decreased driving pressure $(\Delta \mathrm{P})(\mathrm{MD}-6.02$ $\left.\mathrm{cmH}_{2} \mathrm{O}, 95 \% \mathrm{Cl}\left[-8.32,-3.72 \mathrm{cmH}_{2} \mathrm{O}\right], p<0.0001\right)$, Peak pressure (Ppeak) (MD -2.88 $\left.\mathrm{cmH}_{2} \mathrm{O}, 95 \% \mathrm{Cl}\left[-4.60,-1.16 \mathrm{cmH}_{2} \mathrm{O}\right], p=0.001\right)$, and improved PaO $2 / \mathrm{FiO}_{2}$ ( $\mathrm{MD} 32.27 \mathrm{mmHg}, 95 \% \mathrm{Cl}[19.54,45.01 \mathrm{mmHg}], p<0.00001)$. Risk of atelectasis was the same between the two groups. Furthermore, the study suggested that low Vt ventilation was associated with decreases in the risk of acute lung injury (OR $0.05,95 \% \mathrm{Cl}[0.28,0.88], p=0.02)$. Decreased hospital length of stay in the low Vt group occurred when Vt was set $4-5 \mathrm{ml} / \mathrm{kg}(\mathrm{MD}-0.78 \mathrm{~d}, 95 \% \mathrm{Cl}[-1.45,-0.11 \mathrm{~d}], p=0.02)$.

Conclusions: In OLV patients, low Vt ventilation improved $\mathrm{PaO}_{2} / \mathrm{FiO}_{2}$, and it was also associated with decreased blood IL-6, $\Delta \mathrm{P}$, Ppeak, and risk of acute lung injury, when the low Vt was set 4-5 ml/kg hospital length of stay was decreased .

\section{Introduction}

Lung complications are common after general anesthesia surgery and are associated with significantly increased mortality and morbidity[1, 2]. Low tidal volume $(\mathrm{Vt})$ mechanical ventilation in anesthetized patients undergoing abdominal surgery can limit postoperative pulmonary complications[3]. Initial evidence of protective ventilation with low Vt ventilation comes from acute respiratory distress syndrome (ARDS)[4]. Recent research has established the applying of low Vt ventilation to surgical populations without ARDS, with consistent results[5]. Patients of thoracic surgery undergoing one-lung ventilation $(\mathrm{OLV})$ are challenged physiologic and clinical circumstances that complicate the application of lung-protective ventilation with low $\mathrm{Vt}$.

OLV causes significant physiologic mechanisms changes, thus affects the clinical prognosis of patients. These changed physiologic mechanisms are as follows[6-8]: the obligate collapse of the nondependent lung and overdistention of the dependent lung represents inflammatory cascades and is related to high airway pressures; when ventilation is switched from two-lung to OLV, shunt fraction increased, and hypoxemia may occur; because of lower chest wall compliance due to lateral decubitus position compared with two lung ventilation, pulmonary atelectasis occurs more frequently. Therefore, patients of thoracic surgery with OLV are vulnerable to ventilator-induced lung injury and increased length of hospital stay.

The sample sizes of most studies of OLV are small, and these studies primarily focus on reporting physiologic outcomes. Furthermore, due to a paucity of evidence, anesthesiologists implemented different ventilation strategies during OLV[9]. Recently, a study has demonstrated that lung-protective ventilation with recruitment maneuvers and PEEP improved physiologic outcomes in OLV for thoracic surgery[10]. However, it has not been evaluated whether low Vt improved outcomes when it was used during OLV in patients undergoing thoracic surgery. In 2017, El Tahan and his colleagues's study[11] denoted that low Vt of OLV was with no impact on hospital length of stay, while a subsequent study[12] showed that the duration of hospital stay was shorter in low Vt group. The metaanalysis aims to assess the effects of low Vt on the physiology and clinical outcomes of adult surgery patients undergoing OLV.

\section{Methods}

The methods that we used to write the meta-analysis comply with the Preferred Reporting Items for Systematic Reviews and Meta-analyses guidelines[13]

\section{Search Strategies And Study Screening}

The authors searched the PubMed, EMBASE, and the Cochrane Library databases from inception to February 2020 for studies exploring the intraoperative use of OLV with low Vt in patients undergoing thoracic surgery. There were no limits applied for articles published in a different language. The following terms: "protective ventilation or low tidal volume" and "one-lung ventilation or One-Lung Ventilation" were searched. In addition, the authors manually searched the reference lists of relevant studies.

Two reviewers (F.P.X. and Z.H.L.) independently assessed all titles and abstracts and excluded studies that were irrelevant. According to the inclusion and exclusion criteria, the full texts of the remaining articles were then independently reviewed. The priority inclusion criteria were as follows: 1) patients receiving OLV with clearly reported size of $\mathrm{Vt}$; 2) comparison of different $\mathrm{Vt}$ during intraoperative ventilation undergoing thoracic surgery; 3 ) randomized controlled trials (RCT). Studies involving children, lung transplantation, cardiopulmonary bypass, those comparing airway devices, or without definite time of measurement were excluded. For reaching a consensus inclusion, the discrepancies were resolved by consensus and discussion with a third reviewer. According to the included studies, a low Vt was defined as $3-6 \mathrm{~mL} / \mathrm{kg}$ of ideal body weight, and a high Vt was defined as $8-10 \mathrm{~mL} / \mathrm{kg}$ of ideal body weight. Included studies were then analyzed to identify which outcome measures were reported in the studies.

\section{Data Extraction And Quality Assessment}


Two authors performed data extraction according to standardized author-developed data extraction form in Excel. The following data were extracted from included trials: year of the publication, first author, type of patients, side of the operation, Vt category, $\mathrm{PEEP}$ setting, $\mathrm{FiO}_{2}$ during OLV, recruitment maneuver, and physiology or clinical outcomes. For the data presented as a median range, we converted it to mean standard deviation[14].

We evaluated included RCTs using the Cochrane Risk of Bias tool, which include the following items: random sequence generation (selection bias), allocation concealment (selection bias), blinding of the participants and personnel (performance bias), blinding of the outcome assessment (detection bias), incomplete outcome data (attrition bias), selective reporting (reporting bias), and other biases[15]. One author performed data extraction and bias assessment of the included studies, and the extracted data and the risk of bias ware confirmed by the other author. When there was a discrepancy between the two authors, they reached the consensus by discussion.

\section{Statistical analysis}

All statistical pooling of the meta-analysis was performed using RevMan (ver5.1). Physiology outcomes for meta-analysis of Vt were blood interleukin-6 (IL-6), driving pressure $(\Delta \mathrm{P})$, peak pressure (Ppeak), $\mathrm{PaO}_{2} / \mathrm{FiO}_{2}$, and atelectasis; clinical outcomes for meta-analysis of $\mathrm{Vt}$ were hospital length of stay and incidence of acute lung injury. For dichotomous outcomes, the odds ratios (ORs) with corresponding $95 \%$ confidence intervals (Cls) we calculated. The mean difference with the standard deviation was calculated for continuous outcomes. For considering clinical heterogeneity, random effects modeling was chosen as a priority[16]. The author quantified heterogeneity between studies using the $\mathrm{I}^{2}$ statistic[17]. By excluding one study one at a time, the author tested the sensitivity and repeated to analyze the robustness of the aggregated results. A two-sided p-value of less than 0.05 was considered statistically significant.

\section{Results \\ Search results}

Our research identified 2842 studies through database searching, and 25 additional records were identified through other sources. 1023 records remained after duplicates were removed by screening the titles and abstracts. Among them, 934 publications were not relevant and were discarded. The full text of the remaining 80 publications was examined for an assessment; According to the exclusion criteria, 69 publications were ineligible and were excluded. Twelve studies were included in the final meta-analysis (Fig. 1).

\section{Study Characteristics}

We included 12 studies that compared low Vt with high Vt in thoracic surgery patients undergoing OLV. The characteristics of each study are reported in Table 1. The included studies were published between 2005 and 2019. The analysis involved 876 participants, individual study with different samples size ranging from 26 to 343. Low Vt varied from $3 \mathrm{~mL} / \mathrm{kg}$ to $6 \mathrm{~mL} / \mathrm{kg}$ of ideal body weigh, while high Vt was from $8 \mathrm{~mL} / \mathrm{kg} \mathrm{to} 10 \mathrm{~mL} / \mathrm{kg}$ of ideal body weigh. Ten studies applied PEEP varying from $3 \mathrm{cmH}_{2} \mathrm{O}$ to $8 \mathrm{cmH}_{2} \mathrm{O}$ in the low Vt groups. Ten studies did not apply or did not mention applying PEEP in the high Vt groups. The fraction of inspiration $\mathrm{O}_{2}\left(\mathrm{FiO}_{2}\right)$ applied in eight of the studies during the surgery was adjusted according to oxygen saturation or protocol. Three studies administered recruitment maneuvers (RM) in the low Vt group, two studies in the high Vt group. 12[12, 18-28] of these studies reported data on physiology outcomes (IL-6, $\triangle \mathrm{P}, \mathrm{Ppeak}, \mathrm{PaO}_{2} / \mathrm{FiO}_{2}$, atelectasis), and 7 studies[12, 18, 22-24, 26, 27] included data on clinical outcomes (hospital length of stay, the incidence of acute lung injury). The details of the risk of bias assessment are outlined in Fig. 2. 
Table 1

Characteristics of Included Studies

\begin{tabular}{|c|c|c|c|c|c|c|c|c|c|c|c|c|c|}
\hline \multirow[t]{2}{*}{ Study } & \multirow[t]{2}{*}{ Type of Surgery } & \multicolumn{6}{|l|}{ Low Vt } & \multicolumn{6}{|l|}{ High Vt } \\
\hline & & $\begin{array}{l}\text { Number } \\
\text { of } \\
\text { Patients }\end{array}$ & $\begin{array}{l}\text { Time of } \\
\text { Ventilation } \\
\text { (min) }\end{array}$ & $\begin{array}{l}\text { Vt } \\
(\mathrm{ml} / \mathrm{kg}) \\
\text { IBW }\end{array}$ & $\begin{array}{l}\text { PEEP } \\
\text { (cm } \\
\mathrm{H} 20 \text { ) }\end{array}$ & RM & $\mathrm{FiO} 2$ & $\begin{array}{l}\text { Number } \\
\text { of } \\
\text { Patients }\end{array}$ & $\begin{array}{l}\text { Time of } \\
\text { Ventilation } \\
\text { (min) }\end{array}$ & $\begin{array}{l}\mathrm{Vt} \\
(\mathrm{ml} / \mathrm{kg}) \\
\text { IBW }\end{array}$ & $\begin{array}{l}\text { PEEP } \\
\text { (cm } \\
\mathrm{H} 20)\end{array}$ & RM & FiO2 \\
\hline $\begin{array}{l}\text { Ahn } \\
2012^{16}\end{array}$ & $\begin{array}{l}\text { Video-assisted } \\
\text { thoracic surgery }\end{array}$ & 25 & $\begin{array}{l}108.6 \pm \\
36.5\end{array}$ & 6 & 5 & NA & 0.5 & 25 & $\begin{array}{l}115.9 \pm \\
44.0\end{array}$ & 10 & 0 & NA & 1 \\
\hline $\begin{array}{l}\text { Jung } \\
2014^{17}\end{array}$ & $\begin{array}{l}\text { Video assisted } \\
\text { thoracostomy }\end{array}$ & 30 & NA & 6 & 8 & Yes & 1 & 30 & NA & 10 & 0 & No & 1 \\
\hline $\begin{array}{l}\text { Kim } \\
2019^{18}\end{array}$ & $\begin{array}{l}\text { Thoracoscopic } \\
\text { lobectomy }\end{array}$ & 20 & $121 \pm 34$ & 6 & 5 & No & $\begin{array}{l}\text { Adjusted } \\
\text { according } \\
\text { oxygen } \\
\text { saturation }\end{array}$ & 20 & $131 \pm 40$ & 10 & 0 & No & $\begin{array}{l}\text { Adjus } \\
\text { accorı } \\
\text { oxyge } \\
\text { saturé }\end{array}$ \\
\hline $\begin{array}{l}\text { Lin } \\
2008^{19}\end{array}$ & Esophagectomy & 20 & $142 \pm 21$ & $5-6$ & $3-5$ & NA & NA & 20 & $154 \pm 32$ & 10 & 0 & NA & NA \\
\hline $\begin{array}{l}\text { Marret } \\
2018^{20}\end{array}$ & $\begin{array}{l}\text { Lung cancer } \\
\text { surgery }\end{array}$ & 172 & NA & 5 & $5-8$ & Yes & $\begin{array}{l}\text { According } \\
\text { to local } \\
\text { protocol }\end{array}$ & 171 & NA & 10 & 0 & Yes & $\begin{array}{l}\text { Accor } \\
\text { to loci } \\
\text { protoc }\end{array}$ \\
\hline $\begin{array}{l}\text { Maslow } \\
2013^{21}\end{array}$ & $\begin{array}{l}\text { Elective } \\
\text { pulmonary } \\
\text { resection }\end{array}$ & 16 & $42 \pm 8.3$ & 5 & 5 & NA & $\begin{array}{l}\text { Adjusted } \\
\text { according } \\
\text { oxygen } \\
\text { saturation }\end{array}$ & 16 & $46 \pm 9.5$ & 10 & 0 & NA & $\begin{array}{l}\text { Adjus } \\
\text { accorı } \\
\text { oxyge } \\
\text { saturć }\end{array}$ \\
\hline $\begin{array}{l}\text { Michelet } \\
2006^{22}\end{array}$ & $\begin{array}{l}\text { Esophagectomy } \\
\text { for cancer }\end{array}$ & 26 & $85 \pm 29$ & 5 & 5 & NA & $\begin{array}{l}\text { Adjusted } \\
\text { according } \\
\text { oxygen } \\
\text { saturation }\end{array}$ & 26 & $85 \pm 29$ & 9 & 0 & NA & $\begin{array}{l}\text { Adjus } \\
\text { accorı } \\
\text { oxyge } \\
\text { sature }\end{array}$ \\
\hline $\begin{array}{l}\text { Qutub } \\
2014^{23}\end{array}$ & $\begin{array}{l}\text { Video-assisted } \\
\text { thoracic surgery }\end{array}$ & 13 & NA & 4 & 5 & Yes & $\begin{array}{l}\text { Adjusted } \\
\text { according } \\
\text { to oxygen } \\
\text { saturation }\end{array}$ & 13 & NA & 8 & 5 & Yes & $\begin{array}{l}\text { Adjus } \\
\text { accorı } \\
\text { to oxy } \\
\text { saturé }\end{array}$ \\
\hline $\begin{array}{l}\text { Schilling } \\
2005^{24}\end{array}$ & $\begin{array}{l}\text { Thoracic } \\
\text { surgery }\end{array}$ & 16 & $68 \pm 71.9$ & 5 & 0 & NA & $\begin{array}{l}\text { Adjusted } \\
\text { to achieve } \\
\text { a } \mathrm{PaO} 2> \\
80 \mathrm{~mm} \\
\mathrm{Hg}\end{array}$ & 16 & $71 \pm 60.7$ & 10 & 0 & NA & $\begin{array}{l}\text { Adjus } \\
\text { to ach } \\
\text { a PaO } \\
80 \mathrm{mr} \\
\mathrm{Hg}\end{array}$ \\
\hline $\begin{array}{l}\text { Shen } \\
2013^{25}\end{array}$ & Esophagectomy & 53 & $\begin{array}{l}72.2 \pm \\
23.6\end{array}$ & 5 & 5 & NA & $\begin{array}{l}\text { Adjusted } \\
\text { according } \\
\text { oxygen } \\
\text { saturation }\end{array}$ & 48 & $\begin{array}{l}75.0 \pm \\
18.8\end{array}$ & 8 & 0 & NA & $\begin{array}{l}\text { Adjus } \\
\text { accorı } \\
\text { oxyge } \\
\text { saturé }\end{array}$ \\
\hline $\begin{array}{l}\text { Yang } \\
2011^{26}\end{array}$ & $\begin{array}{l}\text { Lung cancer } \\
\text { surgery }\end{array}$ & 50 & $120 \pm 41$ & 6 & 5 & NA & $\begin{array}{l}\text { Adjusted } \\
\text { according } \\
\text { oxygen } \\
\text { saturation }\end{array}$ & 50 & $126 \pm 53$ & 10 & 0 & NA & 1 \\
\hline Ye 2011 & $\begin{array}{l}\text { Lung cancer } \\
\text { surgery }\end{array}$ & 10 & NA & 6 & 5 & NA & 1 & 10 & NA & 8 & 0 & NA & 1 \\
\hline
\end{tabular}

\section{Physiology Outcomes}

12 studies with 876 participants reported the effect of low Vt on physiology outcomes including IL-6, $\Delta \mathrm{P}, \mathrm{Ppeak}, \mathrm{PaO}{ }_{2} / \mathrm{FiO}_{2}$, and atelectasis. The results suggested that OLV with low Vt was associated with decreased IL-6 (MD $-35.51 \mathrm{pg} / \mathrm{ml}, 95 \% \mathrm{Cl}[-66.47,-4.54 \mathrm{pg} / \mathrm{ml}], p=0.02 ; \mathrm{Fig} .3), \Delta \mathrm{P}(\mathrm{MD}-6.02 \mathrm{cmH} \mathrm{O} \mathrm{O}, 95 \%$ $\mathrm{Cl}\left[-8.32,-3.72 \mathrm{cmH}_{2} \mathrm{O}\right], p<0.0001$; Fig. 4), Ppeak (MD -2.88 $\mathrm{cmH}_{2} \mathrm{O}, 95 \% \mathrm{Cl}\left[-4.60,-1.16 \mathrm{cmH}_{2} \mathrm{O}\right], p=0.001$; Figure S1) and increased PaO $2 / \mathrm{FiO} 2(\mathrm{MD}$ $32.27 \mathrm{mmHg}, 95 \% \mathrm{Cl}[19.54,45.01 \mathrm{mmHg}, p<0.00001$; Fig. 5). While, there was not a increase in the risk of atelectasis $(\mathrm{OR} 0.79,95 \% \mathrm{Cl}[0.53,1.17], p=0.24$; Figure S2) with low Vt ventilation. 
When IL- 6 was analyzed in terms of low Vt for less than $6 \mathrm{~mL} / \mathrm{kg}$ or $6 \mathrm{~mL} / \mathrm{kg}$, among those who received a low Vt of less than $6 \mathrm{~mL} / \mathrm{kg}$, there was a significant decrease in the low Vt group than in the high Vt group (MD $-74.62 \mathrm{pg} / \mathrm{ml}, 95 \% \mathrm{Cl}[-110.73,-38.51 \mathrm{pg} / \mathrm{ml}], p<0.0001$; Fig. 3), with possible moderate heterogeneity $\left(I^{2}=32 \%\right)$. However, among those who received a low Vt of $6 \mathrm{~mL} / \mathrm{kg}$, there was no significant difference in IL-6 between low Vt and high $\mathrm{Vt}$ groups (MD $-4.08 \mathrm{pg} / \mathrm{ml}, 95 \% \mathrm{Cl}[-11.08,2.93 \mathrm{pg} / \mathrm{ml}], p=0.25 ; \mathrm{Fig}$. 3). There was also a possibility of substantial heterogeneity $\left(\mathrm{I}^{2}=84.7 \%\right)$ between the subgroups (Fig. 3).

\section{Clinical Outcomes}

Thirteen studies reported acute lung injury and hospital length of stay as clinical outcomes. Overall, there was a significant decrease in the risk of acute lung injury with low Vt ventilation (OR $0.05,95 \% \mathrm{Cl}[0.28,0.88], p=0.02$; Fig. 6). There was a possible low heterogeneity $\left(\mathrm{I}^{2}=0 \%\right)$ between the low $\mathrm{Vt}$ group and the high Vt group (Fig. 6). Meanwhile, the results suggested that low Vt ventilation was not associated with hospital length of stay (MD $-0.53 \mathrm{~d}, 95 \% \mathrm{Cl}[-1.09,-0.03$ d], $p=0.06$; Fig. 7).

According to Vt, four studies with a Vt of $4-5 \mathrm{ml} / \mathrm{kg}$ showed a shorter hospital length of stay in the low Vt group (MD $-0.78 \mathrm{~d}, 95 \% \mathrm{Cl}[-1.45,-0.11 \mathrm{~d}], p=0.02$; Fig. 7), whereas the two studies with a Vt of $6 \mathrm{ml} / \mathrm{kg}$ in the low Vt group showed no difference in hospital length of stay compared with the high Vt group (MD $-0.06 \mathrm{~d}, 95 \% \mathrm{Cl}[-0.96,1.08 \mathrm{~d}], p=0.91$; Fig. 7). There was a possible low heterogeneity between the two subgroups $\left(\mathrm{I}^{2}=45.4 \%\right.$, Fig. 7$)$.

\section{Discussion}

In order to better elaborate the physiology and clinical impact of the Vt in thoracic surgery patients of OLV, we have performed the meta-analysis. The results demonstrate that low Vt ventilation during OLV significantly improved $\mathrm{PaO}_{2} / \mathrm{FiO}_{2}$, and it was associated with decreased blood IL-6, $\triangle \mathrm{P}, \mathrm{Ppeak}$, and risk of acute lung injury. Furthermore, hospital length of stay was decreased in low Vt ventilation when the Vt was set 4-5 ml/kg. Meanwhile, low Vt ventilation had no impact on the risk of atelectasis.

Low Vt ventilation strategy aimed to limit lung overdistension, leading to a reduction in the incidence of ALI along with a shorter hospital stay. Conventional Vt of two lung ventilation may lead to overdistension of the aerated one lung and increase the shear forces generated due to repetitive open and collapse of atelectatic areas. When compared with conventional Vt, a low Vt ventilation strategy is proved to be beneficial for both injured lungs[4] and anesthetized patients[3]. However, there is a lack of large sample randomized controlled studies to evaluate the effect of low Vt on ALI. Our results denoted that the incidence of ALI was low when patients were with one-lung ventilation during thoracic surgery, which was consisted of the findings of Hu's study[29]. In Hu's study, they did not explore hospital stay length, while our study denoted that hospital stay length was decreased when the Vt was set 4-5 ml/kg. However, hospital stay length did not differ between the ventilatory strategies in Lee' s[30] study, for actual body weight was used to set Vt in their research, which may affect the results. Ahn's[18] research showed that low Vt had no advantage on hospital length of stay. The negative results in this study were likely to be explained by the fact that although it was ventilated with low $\mathrm{Vt}$, the platform pressure was not high, less than $20 \mathrm{cmH}_{2} \mathrm{O}$. This result had implied that pressure during ventilation were needed to be taken into account.

In a retrospective study, Amato and his colleges[31] had identified high driving pressure as the risk of outcomes of ARDS patients. In the surgical population, either two lung[32] or one lung[33,34] ventilation, $\Delta \mathrm{P}$ has been identified as a risk factor for the development of postoperative pulmonary complications. Driving pressure equals to elastance times Vt. Thus, it may serve as a surrogate for dynamic alveolar injury. The results of this study showed that low Vt significantly reduced both the driving pressure and peak pressure. Therefore, it can be speculated that low Vt ventilation may be associated with the postoperative pulmonary complications of patients. Further studies are needed to clarify the relationship between Vt, driving pressure, and patient outcomes. In addition, our results denoted other strong indications that lung injury was attenuated by the application of the lower Vt.

High Vt associated with deformation of the alveolar epithelium and cyclic opening of collapsed areas during OLV is thought to local production and release of inflammatory mediators leading to ALI. Inflammatory biomarkers were a direct assessment of lung damage. A decreased inflammatory response was observed in healthy lungs after low Vt ventilation compared with conventional Vt[35]. Previous meta-analysis[11] had envaluated impact of low Vt on OLV patients without inflammatory biomarkers. In our study, the patients who received low Vt ventilation showed decreased serum IL-6, which was indicated as a useful marker of induced injury[36]. Our result was consistent with the previous finding ${ }^{[23]}$ described in patients undergoing esophagectomy, when combined Vt of $5 \mathrm{ml} / \mathrm{kg}$ with positive end-expiratory pressure (PEEP) $5 \mathrm{~cm} \mathrm{H}$ O during one-lung ventilation, resulted in lower levels of IL-6 being released into the serum after the surgery. However, Kim and his colleges ${ }^{[20]}$ did not observe a difference in plasma IL-6. This may due to the calculation of the sample size for this study was not based on postoperative outcomes, making the sample size small. Therefore, the clinical impact on pulmonary inflammation remains further to be investigated.

Hypoxemia during OLV may be prevented by applying a ventilation strategy that avoids alveolar collapse while minimally impairing perfusion of the dependent lung. Strategies to improve ventilation/perfusion ratio and thereby to maintain arterial oxygen tension during OLV[8] in thoracic surgery include using low Vt and positive end-expiratory pressure (PEEP) to the ventilated lung and titrating inspired $\mathrm{FiO}_{2}$ to maintain a SpO $\mathrm{S}_{2}$. In our study, $\mathrm{PaO}_{2} / \mathrm{FiO}_{2}$ was improved under low Vt ventilation. Consistent with Lee' s[30] study that low Vt ventilation was associated with better oxygenation compared with conventional ventilation requiring OLV. While in Liu's study[37], there was no difference in $\mathrm{PaO}_{2} / \mathrm{FiO}_{2}$ between groups, for they compared different modes rather than different $\mathrm{Vt}$ of ventilation. Therefore, large $\mathrm{Vt}$, which was potentially injurious to the lung, do not translate into better oxygenation as compared with low $\mathrm{Vt}$. Low Vt ventilation that keeps the lung open without impeding perfusion improved oxygenation during OLV. 
We also found that postoperative atelectasis was not evident in the low Vt group compared with the conventional Vt group. During intraoperative ventilation, atelectasis may be caused by[38,39] ventilator-associated lung injuries, and the reduction of functional residual capacity consequent to OLV and muscle paralysis. The previous study[30] had shown that lung atelectasis could be reduced by low Vt ventilation when assessed using lung ultrasound. Apart from Vt, the application of PEEP[40] in the low Vt group contributed to the prevention of atelectasis. Considering that PEEP was applied only in the low Vt group among six of the seven included studies, the importance of proper PEEP in the low Vt group may contribute to the prevention of atelectasis in our study.

This meta-analysis also has some limitations. First, the magnitude of hypoxemia generally peaks about 20 minutes after beginning OLV. While, in our study, data were collected at 15 minutes to 2 hours among different studies, which would overestimate the effect of low Vt on oxygenation. Second, there was heterogeneity in the use of PEEP and RM between the two groups among the included studies, for the use of PEEP and RM may associate with improvements in oxygenation and development of ALI. Therefore, analyses were needed to be interpreted with caution due to the heterogeneity.

\section{Conclusions}

This study assessed the physiology and clinical impact of low Vt ventilation during OLV. In OLV patients, low Vt was associated with improvement in $\mathrm{PaO}_{2} / \mathrm{FiO}_{2}$, and with decreased blood IL-6, $\Delta \mathrm{P}$, Ppeak, risk of acute lung injury. Furthermore, low Vt would decrease hospital length of stay of the patients when the Vt was set $4-5 \mathrm{ml} / \mathrm{kg}$, which implied that lower $\mathrm{Vt}$ should be applied in patients of OLV, and further research may require to be confirmed.

\section{Abbreviations}

$\mathrm{Vt}$

tidal volume; OLV = one-lung ventilation; ORs = odds ratios; Cls = confidence intervals; IL-6 = interleukin-6; Ppeak = Peak pressure; ARDS = acute respiratory distress syndrome; $\mathrm{PEEP}=$ positive endexpiratory pressure; $\triangle \mathrm{P}=$ driving pressure

\section{Declarations}

\section{Acknowledgments}

Author contributions: F-P.X. was responsible for conception and design of the study, acquisition, analysis and interpretation of data, and drafting and revising the article for final approval of the version to be published. Z-H.L. and Y-Y.T. were responsible for acquisition and analysis of data, and revising the article. Y.Y.

and H-B.Q. participated in the data analysis, interpretation of the results, and writing of the article. F-M.G. was responsible for the conception and design of the study, analysis and interpretation of data, drafting and revising the article for important intellectual content and final approval of the version to be published. All authors read and approved the manuscript.

\section{Funding:}

The author(s) disclosed receipt of the following financial support for the research, authorship, and publication of this article: Supported by grants from the National Natural Science Foundation of China (grant numbers: 81871602, 81930058).

Availability of data and materials: The data and material used for this meta-analysis are contained in the references.

Ethics approval and consent to participate: Not applicable.

Consent for publication: Not applicable.

Competing interests: The authors declare that they have no competing interests.

\section{References}

1. Lohser J, Ishikawa S. Clinical Management of One-Lung Ventilation. In: Principles and Practice of Anesthesia for Thoracic Surgery. $2011: 83-101$.

2. Canet J, Gallart L, Gomar C, Paluzie G, Vallès J, Castillo J, Sabaté S, Mazo V, Briones Z, Sanchis J. Prediction of postoperative pulmonary complications in a population-based surgical cohort. Anesthesiology. 2010;113(6):1338-50.

3. Futier E, Constantin JM, Paugam-Burtz C, Pascal J, Eurin M, Neuschwander A, Marret E, Beaussier M, Gutton C, Lefrant JY, et al. A trial of intraoperative low-tidal-volume ventilation in abdominal surgery. The New England journal of medicine 2013, 369(5):428-437.

4. Brower RG, Matthay MA, Morris A, Schoenfeld D, Thompson BT, Wheeler A. Ventilation with lower tidal volumes as compared with traditional tidal volumes for acute lung injury and the acute respiratory distress syndrome. N Engl J Med. 2000;342(18):1301-8.

5. Guay J, Ochroch EA, Kopp S. Intraoperative use of low volume ventilation to decrease postoperative mortality, mechanical ventilation, lengths of stay and lung injury in adults without acute lung injury. Cochrane Database Syst Rev. 2018;7(7):Cd011151.

6. Grichnik KP, Shaw A. Update on one-lung ventilation: the use of continuous positive airway pressure ventilation and positive end-expiratory pressure ventilation-clinical application. Curr Opin Anaesthesiol. 2009;22(1):23-30.

7. Della Rocca G, Coccia C. Acute lung injury in thoracic surgery. Curr Opin Anaesthesiol. 2013;26(1):40-6.

8. Karzai W, Schwarzkopf K. Hypoxemia during one-lung ventilation: prediction, prevention, and treatment. Anesthesiology 2009, 110(6):1402-1411. 
9. Kidane B, Choi S, Fortin D, O'Hare T, Nicolaou G, Badner NH, Inculet RI, Slinger P, Malthaner RA. Use of lung-protective strategies during one-lung ventilation surgery: a multi-institutional survey. Annals of translational medicine 2018, 6(13):269.

10. Peel JK, Funk DJ, Slinger P, Srinathan S, Kidane B. Positive end-expiratory pressure and recruitment maneuvers during one-lung ventilation: A systematic review and meta-analysis. J Thorac Cardiovasc Surg 2020.

11. El Tahan MR, Pasin L, Marczin N, Landoni G. Impact of Low Tidal Volumes During One-Lung Ventilation. A Meta-Analysis of Randomized Controlled Trials. J Cardiothorac Vasc Anesth 2017, 31(5):1767-1773.

12. Marret E, Cinotti R, Berard L, Piriou V, Jobard J, Barrucand B, Radu D, Jaber S, Bonnet F. the PPVsg. Protective ventilation during anaesthesia reduces major postoperative complications after lung cancer surgery: A double-blind randomised controlled trial. Eur J Anaesthesiol 2018, 35(10):727-35.

13. Liberati A, Altman DG, Tetzlaff J, Mulrow C, Gøtzsche PC, loannidis JP, Clarke M, Devereaux PJ, Kleijnen J, Moher D. The PRISMA statement for reporting systematic reviews and meta-analyses of studies that evaluate health care interventions: explanation and elaboration. J Clin Epidemiol. 2009;62(10):e134.

14. Hozo SP, Djulbegovic B, Hozo I. Estimating the mean and variance from the median, range, and the size of a sample. BMC medical research methodology 2005, 5:13.

15. Higgins JP, Altman DG, Gøtzsche PC, Jüni P, Moher D, Oxman AD, Savovic J, Schulz KF, Weeks L, Sterne JA. The Cochrane Collaboration's tool for assessing risk of bias in randomised trials. BMJ. 2011;343:d5928.

16. Borenstein M, Hedges LV, Higgins JP, Rothstein HR. A basic introduction to fixed-effect and random-effects models for meta-analysis. Research synthesis methods. 2010;1(2):97-111.

17. Higgins JP, Thompson SG, Deeks JJ, Altman DG. Measuring inconsistency in meta-analyses. BMJ (Clinical research ed) 2003, 327(7414):557-560.

18. Ahn HJ, Kim JA, Yang M, Shim WS, Park KJ, Lee JJ. Comparison between conventional and protective one-lung ventilation for ventilator-assisted thoracic surgery. Anaesthesia and intensive care 2012, 40(5):780-788.

19. Jung JD, Kim SH, Yu BS, Kim HJ. Effects of a preemptive alveolar recruitment strategy on arterial oxygenation during one-lung ventilation with different tidal volumes in patients with normal pulmonary function test. Korean journal of anesthesiology 2014, 67(2):96-102.

20. Kim HJ, Seo JH, Park KU, Kim YT, Park IK, Bahk JH. Effect of combining a recruitment maneuver with protective ventilation on inflammatory responses in video-assisted thoracoscopic lobectomy: a randomized controlled trial. Surg Endosc. 2019;33(5):1403-11.

21. Lin WQ, Lu XY, Cao LH, Wen LL, Bai XH, Zhong ZJ. [Effects of the lung protective ventilatory strategy on proinflammatory cytokine release during one-lung ventilation]. Ai zheng $=$ Aizheng $=$ Chinese journal of cancer 2008, 27(8):870-873.

22. Maslow AD, Stafford TS, Davignon KR, Ng T. A randomized comparison of different ventilator strategies during thoracotomy for pulmonary resection. J Thorac Cardiovasc Surg. 2013;146(1):38-44.

23. Michelet P, D'Journo XB, Roch A, Doddoli C, Marin V, Papazian L, Decamps I, Bregeon F, Thomas P, Auffray JP. Protective ventilation influences systemic inflammation after esophagectomy: a randomized controlled study. Anesthesiology. 2006;105(5):911-9.

24. Qutub H, El-Tahan MR, Mowafi HA, El Ghoneimy YF, Regal MA, Al Saflan AA. Effect of tidal volume on extravascular lung water content during one-lung ventilation for video-assisted thoracoscopic surgery: a randomised, controlled trial. Eur J Anaesthesiol. 2014;31(9):466-73.

25. Schilling T, Kozian A, Huth C, Buhling F, Kretzschmar M, Welte T, Hachenberg T. The pulmonary immune effects of mechanical ventilation in patients undergoing thoracic surgery. Anesth Analg. 2005;101(4):957-65. table of contents.

26. Shen $Y$, Zhong M, Wu W, Wang H, Feng M, Tan L, Wang Q. The impact of tidal volume on pulmonary complications following minimally invasive esophagectomy: a randomized and controlled study. J Thorac Cardiovasc Surg. 2013;146(5):1267-73. discussion 1273 - 1264.

27. Yang M, Ahn HJ, Kim K, Kim JA, Yi CA, Kim MJ, Kim HJ. Does a protective ventilation strategy reduce the risk of pulmonary complications after lung cancer surgery?: a randomized controlled trial. Chest 2011, 139(3):530-537.

28. Ye FF, Li LW. [Effects of different ventilation modes for one-lung ventilation anesthesia on respiratory function and $F(A) / F(I)$ changes during sevoflurane inhalation]. Nan fang yi ke da xue xue bao = Journal of Southern Medical University 2011, 31(4):714-717.

29. Hu XY, Du B. Lung-protective ventilation during one-lung ventilation: known knowns, and known unknowns. J Thorac Dis. 2019;11(Suppl 3):237-40.

30. Lee JH, Bae JI, Jang YE, Kim EH, Kim HS, Kim JT. Lung protective ventilation during pulmonary resection in children: a prospective, single-centre, randomised controlled trial. British journal of anaesthesia 2019, 122(5):692-701.

31. Amato MB, Meade MO, Slutsky AS, Brochard L, Costa EL, Schoenfeld DA, Stewart TE, Briel M, Talmor D, Mercat A, et al. Driving pressure and survival in the acute respiratory distress syndrome. The New England journal of medicine 2015, 372(8):747-755.

32. Neto AS, Hemmes SN, Barbas CS, Beiderlinden M, Fernandez-Bustamante A, Futier E, Gajic O, El-Tahan MR, Ghamdi AA, Günay E, et al. Association between driving pressure and development of postoperative pulmonary complications in patients undergoing mechanical ventilation for general anaesthesia: a meta-analysis of individual patient data. The Lancet Respiratory medicine. 2016;4(4):272-80.

33. Blank RS, Colquhoun DA, Durieux ME, Kozower BD, McMurry TL, Bender SP, Naik BI. Management of One-lung Ventilation: Impact of Tidal Volume on Complications after Thoracic Surgery. Anesthesiology. 2016;124(6):1286-95.

34. Park M, Ahn HJ, Kim JA, Yang M, Heo BY, Choi JW, Kim YR, Lee SH, Jeong H, Choi SJ, et al. Driving Pressure during Thoracic Surgery: A Randomized Clinical Trial. Anesthesiology 2019, 130(3):385-393.

35. Terragni PP, Del Sorbo L, Mascia L, Urbino R, Martin EL, Birocco A, Faggiano C, Quintel M, Gattinoni L, Ranieri VM. Tidal volume lower than 6 ml/kg enhances lung protection: role of extracorporeal carbon dioxide removal. Anesthesiology. 2009;111(4):826-35.

36. Dreyfuss D, Rouby JJ. Mechanical ventilation-induced lung release of cytokines: a key for the future or pandora's box? Anesthesiology 2004, 101(1):1-3. 
37. Liu Z, Liu X, Huang Y, Zhao J. Intraoperative mechanical ventilation strategies in patients undergoing one-lung ventilation: a meta-analysis. SpringerPlus 2016, 5(1):1251.

38. Hedenstierna G, Edmark L. The effects of anesthesia and muscle paralysis on the respiratory system. Intensive care medicine 2005, 31(10):1327-1335.

39. Kozian A, Schilling T, Fredén F, Maripuu E, Röcken C, Strang C, Hachenberg T, Hedenstierna G. One-lung ventilation induces hyperperfusion and alveolar damage in the ventilated lung: an experimental study. British journal of anaesthesia 2008, 100(4):549-559.

40. Östberg E, Thorisson A, Enlund M, Zetterström H, Hedenstierna G, Edmark L. Positive End-expiratory Pressure Alone Minimizes Atelectasis Formation in Nonabdominal Surgery: A Randomized Controlled Trial. Anesthesiology 2018, 128(6):1117-1124.

\section{Figures}

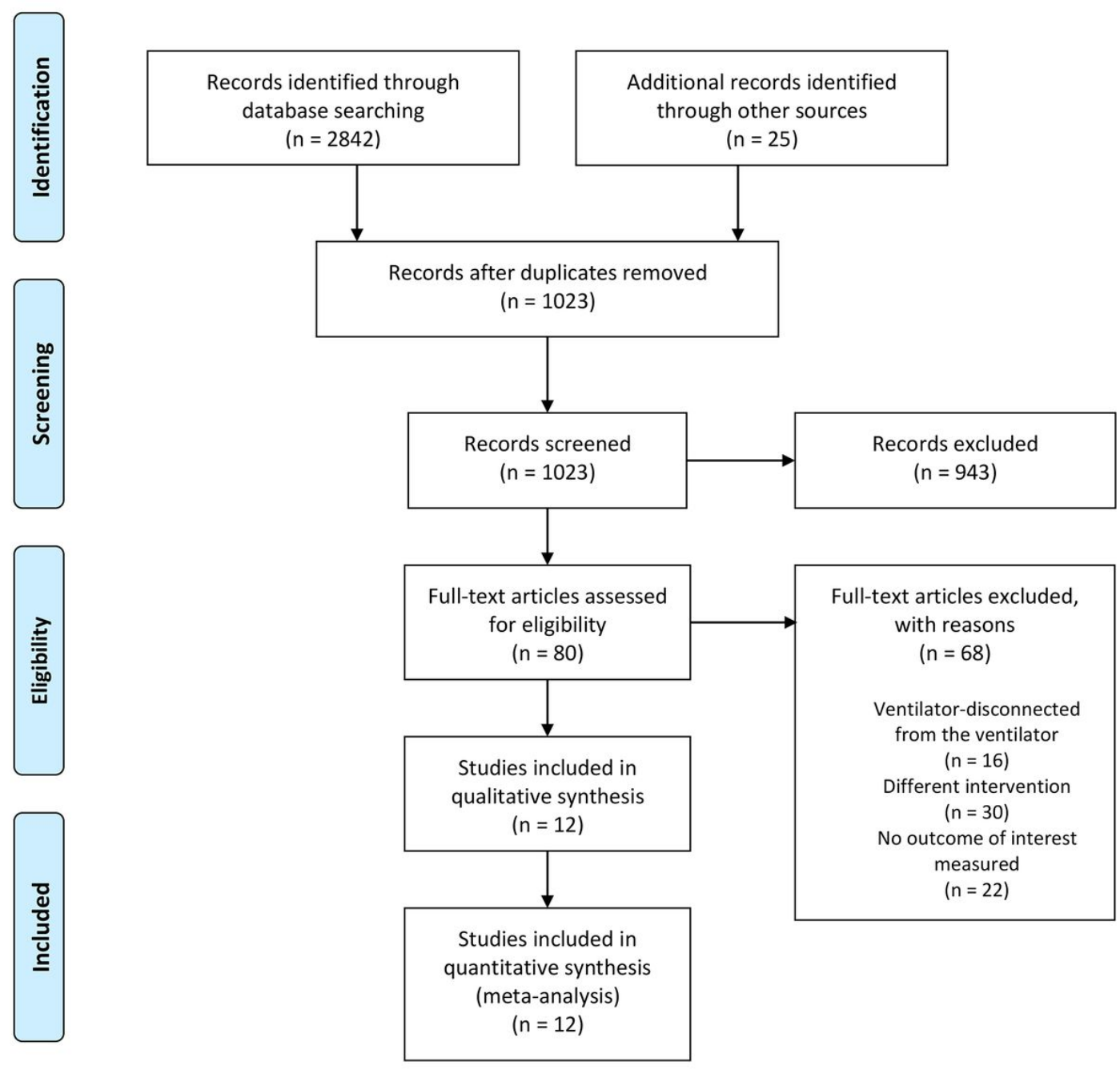

Figure 1

PRISMA flow diagram of the selected trials. 


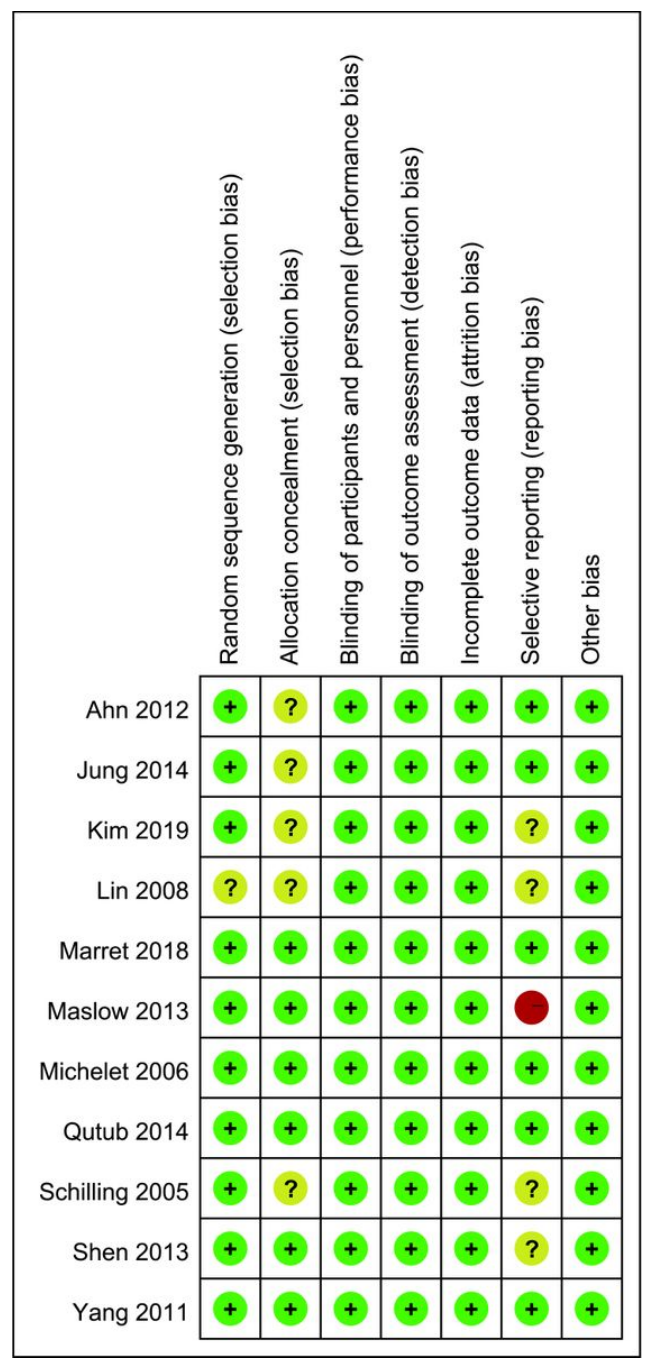

Figure 2

Risk of bias summary of the included studies. The reviews' judgements about seven risk of bias item for each study. Red indicates high risk; yellow indicates unclear risk; green indicates low risk.

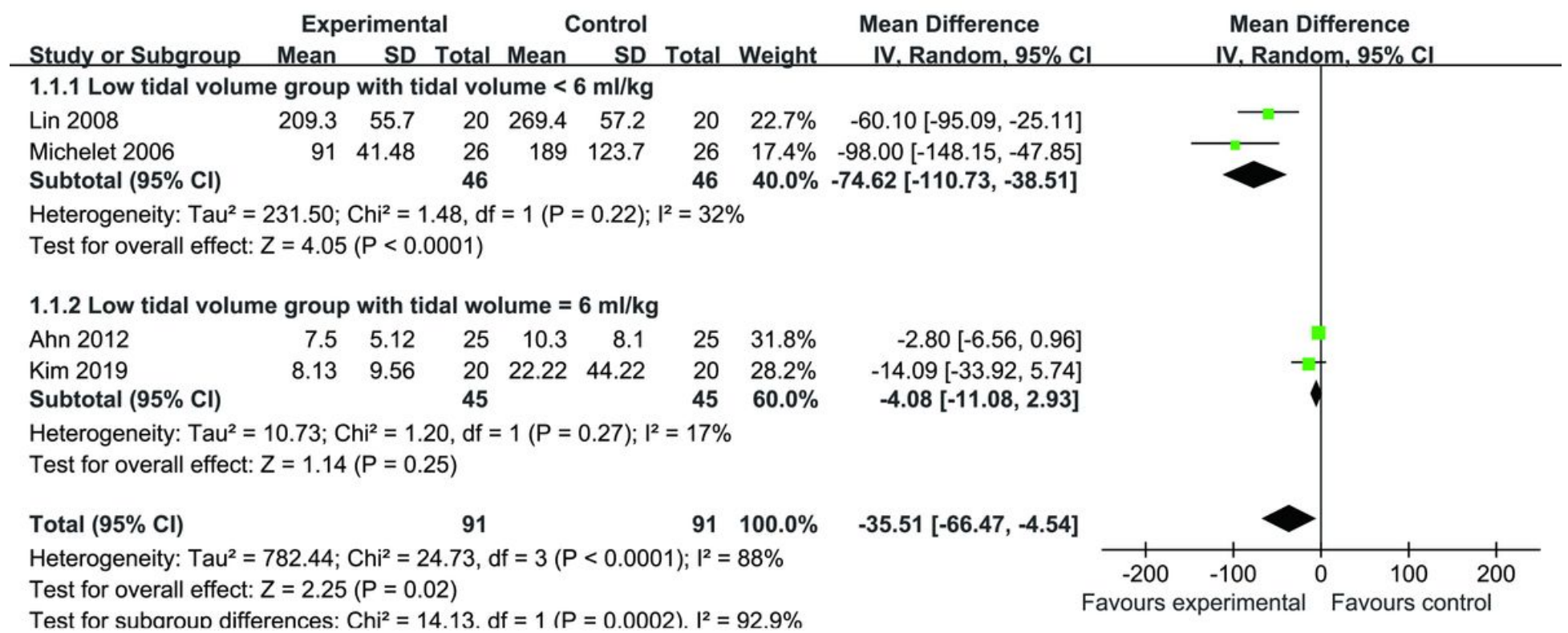

Figure 3

The association of low tidal volume ventilation and IL-6 in surgery patients undergoing one-lung ventilation. 


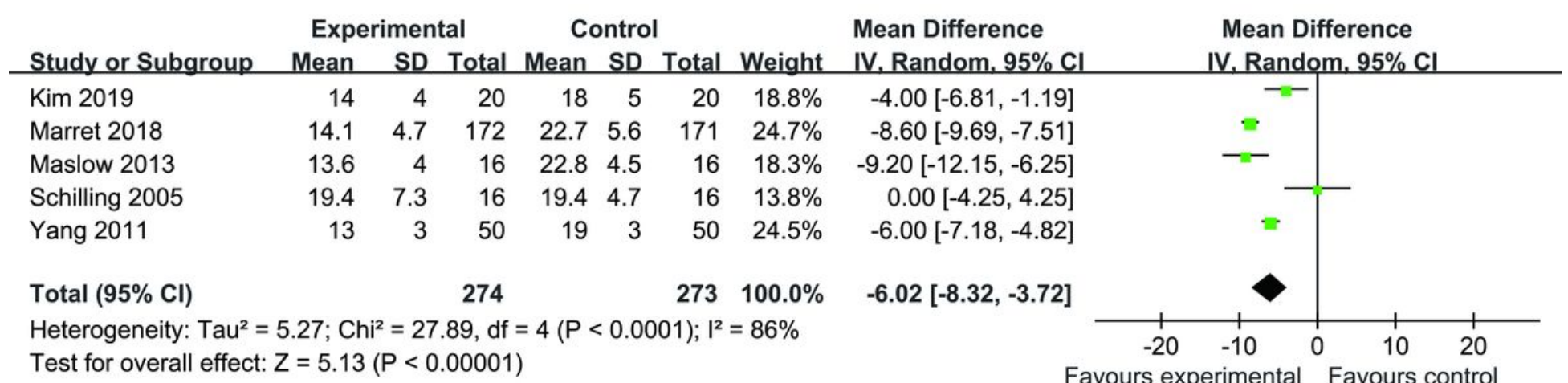

Figure 4

The association of low tidal volume ventilation and driving pressure in surgery patients undergoing one-lung ventilation.

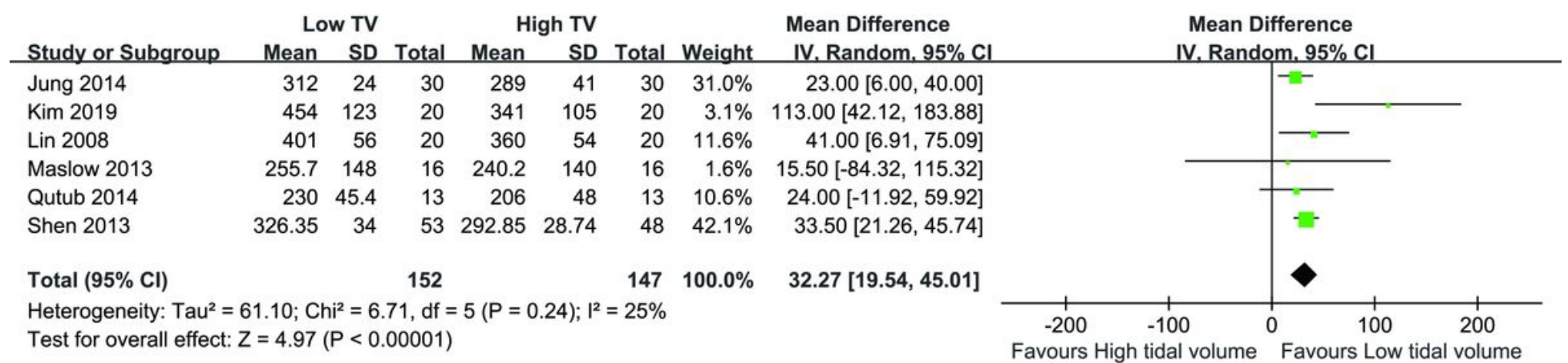

Figure 5

The association of low tidal volume ventilation and $\mathrm{PaO} 2 / \mathrm{FiO} 2$ in surgery patients undergoing one-lung ventilation.

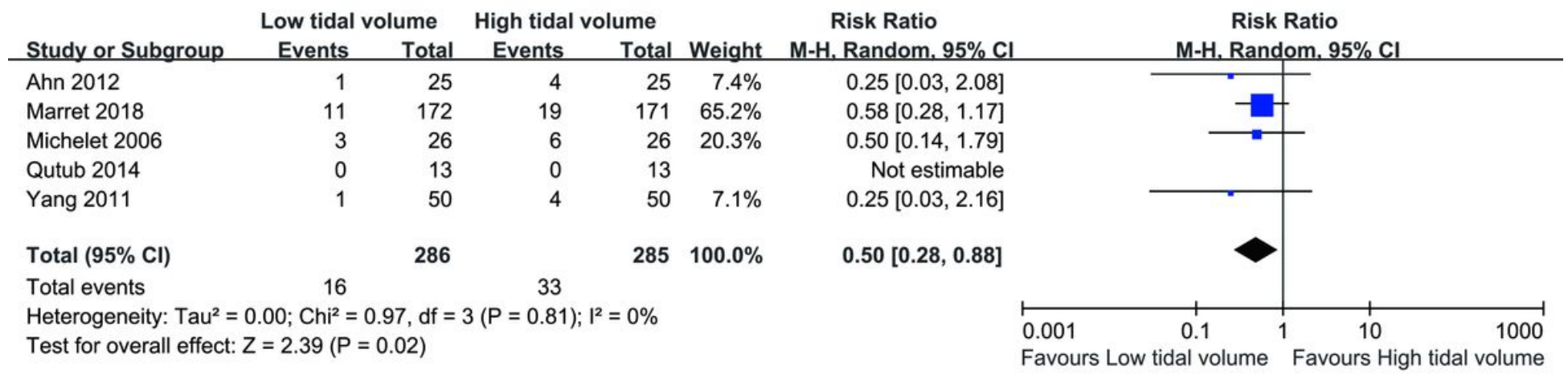

Figure 6

The association of low tidal volume ventilation and the risk of acute lung injury in surgery patients undergoing one-lung ventilation. 


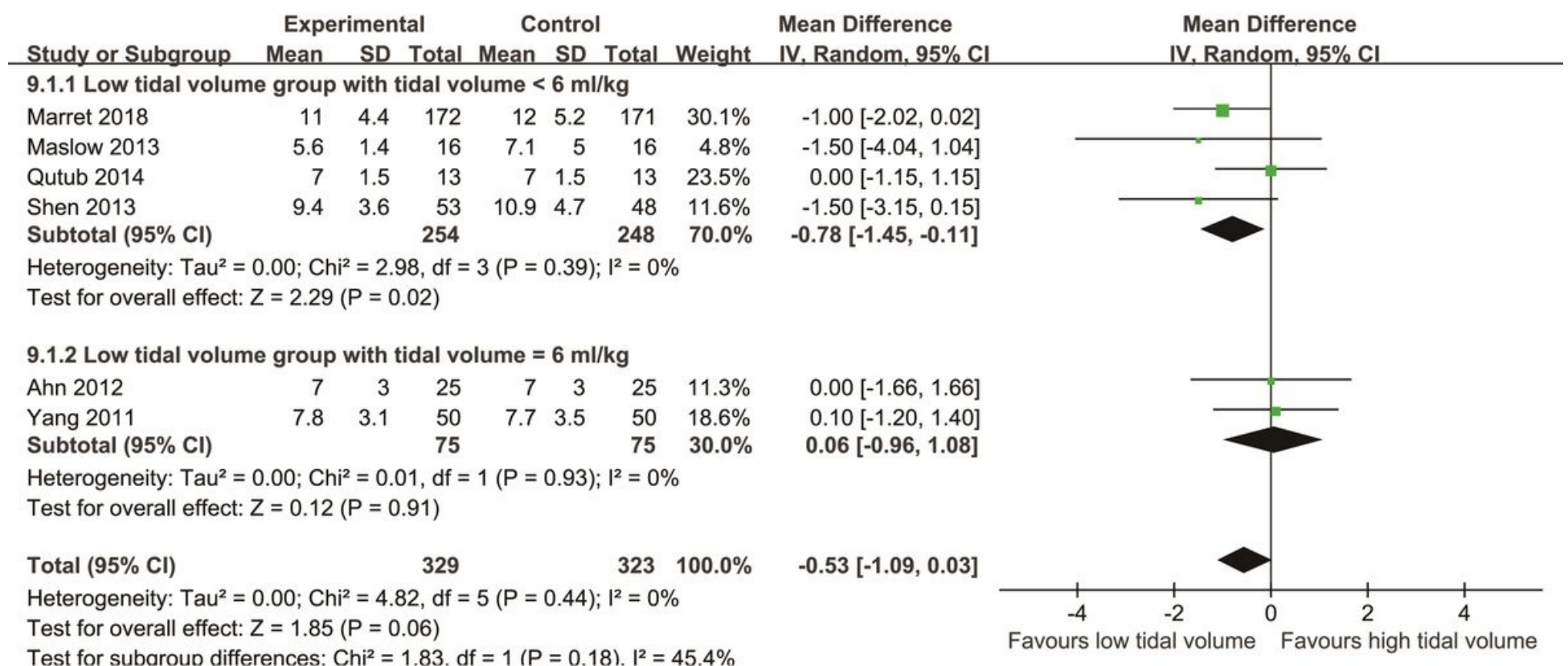

Figure 7

The association of low tidal volume ventilation and hospital length of stay in surgery patients undergoing one-lung ventilation.

\section{Supplementary Files}

This is a list of supplementary files associated with this preprint. Click to download.

- figureS2atelectasis.tif

- figureS1Ppeak.tif 